\title{
Non-Pharmacological Therapy for Atrial Fibrillation: Managing the Left Atrial Appendage
}

\author{
Sushil Allen Luis, Damian Roper, Alexander Incani, \\ Karl Poon, Haris Haqqani, and Darren L. Walters \\ Department of Cardiology, The Prince Charles Hospital, Rode Road, Chermside, QLD 4032, Australia \\ Correspondence should be addressed to Damian Roper, damian_roper@health.qld.gov.au
}

Received 6 January 2012; Revised 12 March 2012; Accepted 12 March 2012

Academic Editor: P. Holvoet

Copyright $\odot 2012$ Sushil Allen Luis et al. This is an open access article distributed under the Creative Commons Attribution License, which permits unrestricted use, distribution, and reproduction in any medium, provided the original work is properly cited.

\begin{abstract}
The prevalence of atrial fibrillation (AF) is increasing in parallel with an ageing population leading to increased morbidity and mortality. The most feared complication of AF is stroke, with the arrhythmia being responsible for up to $20 \%$ of all ischemic strokes. An important contributor to this increased risk of stroke is the left atrial appendage (LAA). A combination of the LAA's unique geometry and atrial fibrillation leads to low blood flow velocity and stasis, which are precursors to thrombus formation. It has been hypothesized for over half a century that excision of the LAA would lead to a reduction in the incidence of stroke. It has only been in the last 20-25 years that the knowledge and technology has been available to safely carry out such a procedure. We now have a number of viable techniques, both surgical and percutaneous, which will be covered in this paper.
\end{abstract}

\section{Introduction}

Atrial fibrillation $(\mathrm{AF})$ is the most prevalent arrhythmia seen in clinical practice with over 2.2 million people in the United States being affected [1]. Given the association of AF with advancing age, this figure is predicted to increase significantly over the years to come, in line with an aging population. By 40 years of age, the lifetime risk of a man developing $\mathrm{AF}$ is $26 \%$ and a woman $23 \%$ [2]. Although most patients with AF tolerate it well, in a significant proportion of patients the arrhythmia can lead to a substantial reduction in quality of life. The most significant complication, feared by both patient and medical staff, is that of stroke. A stroke in a patient with $\mathrm{AF}$ has a poorer prognosis than in a patient without AF [3]. The rhythm had been shown to increase a patient's risk of an ischemic stroke by $4-5$ fold [4]. Additionally, AF has been shown to be accountable for up to $20 \%$ of all ischemic strokes [5].

Oral anticoagulant therapy, most commonly with warfarin, has been used to reduce the risk of stroke in patients with nonvalvular AF who are at high risk of thromboembolism [6]. Overall, warfarin is underused in these patients mainly due to patient and health practitioner concerns about the increased risk of significant bleeding with aggressive anticoagulation. Clinical data has suggested that only 50 $60 \%$ of patients who clinically should be prescribed warfarin are actually taking it [7]. Furthermore, clinical trials have demonstrated that a significant proportion of patients who are taking warfarin, are not adequately anticoagulated placing them at an increased risk of stroke. There are now alternative medications to warfarin, which are available. Apixaban is an oral factor Xa inhibitor, which has been shown to be superior to warfarin in preventing stroke or systemic embolism in patients with nonvalvular AF (1.27\% per year versus $1.60 \% ; P=0.01$ for superiority) [8]. Dabigatran is a direct thrombin inhibitor and is available in two different doses. The Re-ly trial included 18,113 patients with AF and a risk of stroke. Patients were randomized to receive either warfarin, dabigatran $110 \mathrm{mg}$ twice daily or $150 \mathrm{mg}$ twice daily. It showed that the lower $110 \mathrm{mg}$ dose had similar rates of stroke and systemic embolism to warfarin (1.52\% per year versus $1.69 \% ; P<0.001$ for noninferiority). Furthermore, the higher $150 \mathrm{mg}$ dose was shown to be superior to warfarin ( $1.11 \%$ per year versus $1.69 \% ; P<0.001$ for superiority) [9]. 
These agents tend to have a lower incidence of bleeding with more convenient dosing regimens without the need for intensive monitoring. However, these agents would not benefit those patients who have a contraindication to anticoagulation, which incorporates between $14-44 \%$ of patients with AF who are at risk of stroke [10]. Even with adequate anticoagulation, the risk of stroke is not abolished. The annual incidence of stroke in patients therapeutically warfarinised is $2-5 \%$ [11]. These issues have led to an increased interest in alternative treatment strategies to help reduce the risk of stroke in these patients. The main focus of this interest is on the left atrial appendage (LAA). It has been shown that more than $90 \%$ of thrombi in patients with nonrheumatic, nonvalvular AF are located within this cavity [12]. The LAA forms during the 3rd week of gestation and temporarily acts as the left atrium. An outpouching of the pulmonary veins develops into the true left atrium [13]. The size and morphology of the LAA varies from person to person and has been measured anywhere from 0.77 to $19.27 \mathrm{~cm}^{3}$. The LAA is often described as being redundant. A number of studies have shown that it plays an important role in the regulation of the intravascular volume status as well as hemodynamic conditions. Excision of the LAA is thought to lead to a reduction in the incidence of stroke in patients with AF. New techniques have emerged which have enabled this process to be done percutaneously without exposing patients to high-risk invasive surgery. Due to the complexity and variability of the LAA anatomy, multimodality imaging techniques play an integral role in the workup of these patients and directing percutaneous closure. This is particularly important to ensure correct sizing of a device and reduce the risk of complications such as device embolisation or free-wall perforation.

\section{Surgical Options}

Historically, obliteration of the left atrial appendage was first used in conjunction with mitral valvotomy, prior to the utilization of cardiopulmonary bypass. Madden carried out the first LAA surgical excision in humans in 1949, publishing 2 cases the same year [14]. Initial results were not promising. The first recorded cases had unacceptably high complication rates, and interest in the procedure waned [15]. Interest in surgical treatment of AF reignited when James Cox introduced the Cox-Maze procedure at the Barnes-Jewish Hospital, St. Louis, in 1987. This helps to terminate AF by making multiple deep incisions in both atria in an attempt to block the electrical pathways needed to sustain the arrhythmia. Additionally the Maze procedure usually includes excision or closure of the LAA. A number of improvements have been made since, resulting in the Cox-Maze III procedure, which is still used in clinical practice today [16-19].

The success of the Maze procedure was illustrated in a retrospective analysis by Cox et al. [20] looking at patients who underwent the procedure for AF which had been unsuccessfully treated medically. Three hundred and six patients were included over an 11-year period, of which 58 had either a previous stroke or transient ischemic attack. Two patients were noted to have perioperative strokes $(0.7 \%)$ and of the 265 patients who were followed up for up to 11 years, only 1 patient was recorded as having had a stroke.

A number of different surgical methods have been used to close the LAA. There are 2 general techniques adopted. Firstly, excision of the LAA can be performed by either removing the LAA and oversewing or a stapled excision. Secondly, exclusion of the LAA can be achieved with sutures or clips on either the endocardial or epicardial surface, isolating the LAA from the left atrium. Additionally, small case series have been reported using a thoracoscopic approach for exclusion of the left atrial appendage without the need for an open sternotomy. The success of each method has been highly scrutinized as clinical evidence has questioned their success.

The Left Atrial Appendage Occlusion Study included 77 patients undergoing CABG [21]. They were randomized to either LAA occlusion or control. The surgical management of the LAA involved either stapled exclusion or suture ligation. The surgery was deemed successful in $72 \%$ of the stapled exclusion group compared with $45 \%$ in the suture ligation group. The predominant reason for failure in the group that underwent suture ligation appeared to unsatisfactory closure, with persistent Doppler flow within the appendage seen on echocardiography. Furthermore, incomplete closure is likely to be more detrimental than not attempting surgery. A follow-up study looking at patients who have undergone surgical LAA closure showed that $41 \%$ of patients with an unsuccessful closure had a thrombus within the LAA on transesophageal echocardiography [22]. The study looked at 137 patients who had either LAA excision $(52$ patients $=38 \%)$ or exclusion $(85$ patents $=$ $62 \%$ ), of which 73 were sutured, and 12 were stapled. There was a success rate of only $40 \%$ (55/137 patients). Surgical excision was more successful than both suture and staple exclusion (73\% versus $23 \%$ versus $0 \%$, resp.).

The poor success of certain LAA exclusion techniques had previously been suggested by a study looking at a group of 50 patients who had undergone mitral valve surgery in addition to ligation of the LAA [23]. A transœesophageal echocardiogram was performed at a variable time after procedure, varying from immediately postoperatively to 13 years later. Partial ligation was seen in 36\% (18/50 patients) of patients. Of these, $50 \%$ (9/18 patients) demonstrated spontaneous echo contrast or thrombus within the LAA, and 22\% (4/18 patients) had experienced a thromboembolic event.

The FDA has approved the use of the AtriClip device (Articure, West Chester, OH, USA) for closure of the LAA. It consists of 2 rigid titanium tubes with elastic nitinol springs covered with a knit-braided sheath. The LAA is inserted into the device, which then clips at the base, separating the appendage from the left atrium. The initial trial assessing the safety and efficacy of the device was carried out in Europe [24]. It included 34 patients with AF who were undergoing elective cardiac surgery via a median sternotomy. Patients underwent computed tomography studies to assess the device location as well as looking for evidence of blood flow within the LAA. Although operative mortality was $8.8 \%$, none of the deaths were attributable to the device. All patients had successful LAA closure at 3 months. There 
were no reports of stroke or transient ischemic attacks during the follow-up period. A further nonrandomized, prospective multicenter trial was performed in the United States called the EXCLUDE trial [25]. Again, the study population was composed of patients who were undergoing primary elective cardiac operations with a median sternotomy. Additionally they had to have either AF or have an increased risk of stroke, as measured by the CHADS2 scoring system (CHADS2 >2) [26]. 71 patients were enrolled across 7 US centers with 1 patient being excluded due to inappropriate LAA anatomy. LAA exclusion was deemed successful in 67 of the remaining 70 patients $(96 \%)$. By the 3-month followup, 61 patients were able to undergo further imaging by either transesophageal echocardiography or computed tomography. At followup, over $98 \%$ of patients had successful exclusion of the LAA. There were no adverse advents attributable to the AtriClip procedure.

Newer surgical techniques are still currently under investigation in an attempt to improve success rates of LAA closure. One such technique involves invaginating the LAA into the left atrium prior to applying a purse-string suture along the base of the LAA [27]. Once this is in place, the LAA is pulled outwards again and the orifice closed with a second running suture. This procedure has only been reported on 8 patients, and followup imaging is still pending; however, the authors remain optimistic about its potential.

Current practice focuses on the excision of the LAA, given its higher success rates. This usually involves a median sternotomy and is usually best used in patients who require an additional cardiac surgery, in light of the associated surgical risks. As techniques improve and procedures become less invasive, this may well change. In light of the paucity of longterm follow-up data following surgical LAA excision and exclusion: further research is required to define long-term outcomes and need for ongoing anticoagulation following these approaches.

\section{Percutaneous Management}

There are a number of devices that are available for closure of the left atrial appendage (see Table 1). Only the WATCHMAN device has been subjected to a randomized controlled trial against a warfarin control group; with remaining devices being assessed by registry data or prospective trials to assess safety and efficacy. Just three of these devices are currently available for clinical use. These include the LARIAT suture delivery system, the WATCHMAN device, and the AMPLATZER Cardiac Plug. The LARIAT suture delivery system is the only device that has, at this time, received both United States Food and Drug Administration (FDA) and European Conformité Européenne (CE) mark regulatory approval. The other two devices carry European CE mark approval for their use. The AMPLATZER Cardiac Plug approval was based on the available registry data. In Australia, the Therapeutic Goods Administration has approved the use of these two devices.

The antiplatelet and anticoagulant regimens used in the clinical trials varied depending on the device (see Table 2).

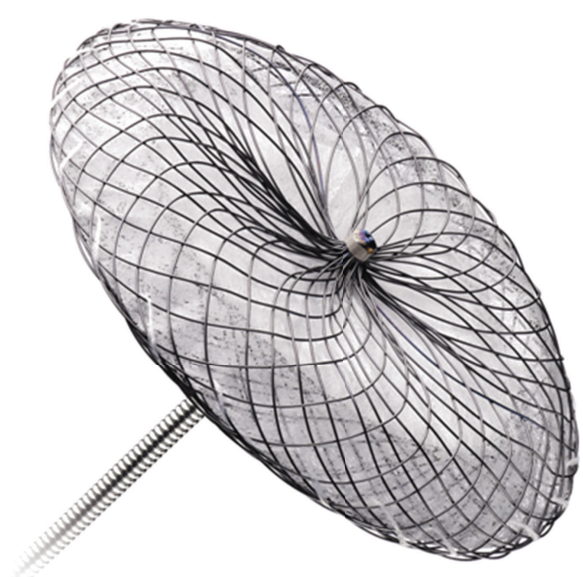

Figure 1: AMPLATZER septal occluder. (AMPLATZER and St. Jude Medical, Inc. Reprinted with permission of St. Jude Medical, (C) 2011. All rights reserved).

3.1. AMPLATZER Septal Occluder. The AMPLATZER Septal Occluder (St. Jude Medical, Plymouth, MN, USA) was initially designed for patent foramen ovale and atrial septal defect closure. A small trial of 16 patients across 4 centres assessed its use in left atrial appendage occlusion [28]. A standard AMPLATZER atrial septal defect occluder with a neck a few millimetres smaller than the neck of the left atrial appendage was selected. The left disk of the occluder was released within the left atrial appendage and right disk released at the left atrial appendage entrance. A single technical failure occurred due to inappropriate device sizing resulting in device embolization and requiring cardiac surgery for device retrieval. Over a short device follow-up period of just 4 months, there were no adverse events attributable to the device implantation or thromboembolic events noted (Figure 1).

No further clinical trials have been conducted using this system for left atrial appendage occlusion. A new device, the AMPLATZER Cardiac Plug, has been designed by the same manufacturer and is currently undergoing clinical trial (see below).

3.2. PLAATO. The PLAATO system (eV3, Plymouth, MN, USA) consists of a percutaneously delivered self-expanding nitinol cage covered with an expanded polytetrafluoroethylene and 3 rows of anchors, delivered via a transseptal approach.

Initial assessment in a canine model demonstrated proof of concept with left atrial appendage occlusion being achieved in all cases. Complete healing over the device's membrane surface was demonstrated on both gross and histological examination in $90 \%$ by 1 month and in all cases by 3-month follow-up [29].

Subsequent human trials demonstrated a high procedural success rate with successful implantation in 108 of the 111 patients enrolled $(97.3 \%, 95 \%$ confidence interval (CI) $92.3 \%$ to $99.4 \%$ ) [30]. Patients were treated with aspirin (300 to $325 \mathrm{mg}$ ) indefinitely. North American patients also 
TABLE 1: Summary of percutaneous devices.

\begin{tabular}{|c|c|c|c|c|c|c|c|}
\hline Device & Study & Design & $\begin{array}{c}\text { Number of } \\
\text { patients }\end{array}$ & Inclusion criteria & Mean F/U & Results & Comments \\
\hline LARIAT & $\begin{array}{l}\text { Lee et al. } \\
\text { [39] }\end{array}$ & Prospective & 82 & $\begin{array}{l}\text { AF; C/I to warfarin } \\
\text { or intolerance to } \\
\text { warfarin or pts } \\
\text { who have had an } \\
\text { embolic event on } \\
\text { whilst on warfarin }\end{array}$ & 3 months & $\begin{array}{l}96 \% \text { of patients } \\
\text { with successful } \\
\text { closure } \\
\text { continued to } \\
\text { have complete } \\
\text { closure at } 1 \\
\text { month }\end{array}$ & $\begin{array}{l}\text { (i) Requires both endocardial and } \\
\text { epicardial access } \\
\text { (ii) Unsuitable in patients with } \\
\text { possible pericardial adhesions } \\
\text { (e.g., prior history of coronary } \\
\text { artery bypass surgery, valvular } \\
\text { surgery, pericarditis, and chest } \\
\text { radiotherapy) } \\
\text { (iii) Clinical trial data pending } \\
\text { (iv) FDA and CE mark } \\
\text { APPROVED for commercial use }\end{array}$ \\
\hline WATCHMAN & $\begin{array}{l}\text { Reddy et al. } \\
\text { (PROTECT } \\
\text { AF) }[33]\end{array}$ & RCT & 707 & $\begin{array}{l}\text { Permanent or } \\
\text { paroxysmal AF; } \\
\text { CHADS2 } \geq 1 ; \\
\text { suitable for } \\
\text { warfarin }\end{array}$ & 18 months & $\begin{array}{l}\text { Probability of } \\
\text { noninferiority } \\
\text { of the } \\
\text { intervention } \\
\text { was more than } \\
99.9 \%\end{array}$ & $\begin{array}{l}\text { (i) Efficacy demonstrated in } \\
\text { clinical trial } \\
\text { (ii) CE mark APPROVED for } \\
\text { commercial use }\end{array}$ \\
\hline $\begin{array}{l}\text { AMPLATZER } \\
\text { cardiac plug }\end{array}$ & $\begin{array}{l}\text { Park et al. } \\
\text { [35] }\end{array}$ & Registry & 141 & $\begin{array}{l}\text { Permanent or } \\
\text { paroxysmal AF }\end{array}$ & $\begin{array}{l}24 \text { hours } \\
\text { after- } \\
\text { implantation }\end{array}$ & $\begin{array}{l}\text { Stroke 2.1\% } \\
\text { Device } \\
\text { embolisation } \\
1.4 \% \\
\text { Pericardial } \\
\text { tamponade } \\
3.5 \%\end{array}$ & $\begin{array}{l}\text { (i) Clinical trial data pending } \\
\text { (ii) CE mark APPROVED for } \\
\text { commercial use }\end{array}$ \\
\hline $\begin{array}{l}\text { AMPLATZER } \\
\text { septal occluder }\end{array}$ & $\begin{array}{l}\text { Meier et al. } \\
\mathrm{r} \quad[28]\end{array}$ & Prospective & 16 & $\begin{array}{l}\text { Permanent or } \\
\text { paroxysmal AF; } \\
\text { C/I to warfarin }\end{array}$ & 4 months & $\begin{array}{l}\text { TIA/stroke } 0 \% \\
\text { Device } \\
\text { embolisation } \\
6.3 \%\end{array}$ & $\begin{array}{l}\text { (i) Not a dedicated LAA occluder } \\
\text { (ii) Has been superseded by the } \\
\text { AMPLATZER Cardiac Plug for } \\
\text { LAA occlusion } \\
\text { (iii) Not in Commercial use }\end{array}$ \\
\hline \multirow[t]{2}{*}{ PLAATO } & $\begin{array}{l}\text { Ostermayer } \\
\text { et al. [30] }\end{array}$ & Prospective & 111 & $\begin{array}{l}\text { Permanent } \\
\text { nonrheumatic AF; } \\
\text { patients at risk for } \\
\text { stroke; C/I to } \\
\text { warfarin }\end{array}$ & 10 months & $\begin{array}{l}\text { TIA/stroke } \\
2.2 \%\end{array}$ & \multirow[t]{2}{*}{$\begin{array}{l}\text { (i) No longer available for clinical } \\
\text { use }\end{array}$} \\
\hline & $\begin{array}{l}\text { Block et al. } \\
\text { [31] }\end{array}$ & Prospective & 64 & $\begin{array}{l}\text { Permanent or } \\
\text { paroxysmal AF; } \\
\text { CHADS } 2 \geq 2 ; \\
\text { C/I to warfarin }\end{array}$ & 5 years & Stroke: $3.8 \%$ & \\
\hline $\begin{array}{l}\text { Coherex Wave } \\
\text { Crest }\end{array}$ & $\begin{array}{c}\text { Muller } \\
\text { (currently } \\
\text { recruiting) } \\
{[36]}\end{array}$ & Prospective & $\begin{array}{l}52- \\
\text { actively } \\
\text { recruiting }\end{array}$ & $\begin{array}{l}\text { Permanent or } \\
\text { paroxysmal } \\
\text { nonvalvular AF; } \\
\text { CHADS2 } \geq 1\end{array}$ & & $\begin{array}{l}\text { Data available } \\
\text { on } 10 \text { cases } \\
\text { only, } 1 \text { embolic } \\
\text { event }\end{array}$ & $\begin{array}{l}\text { (i) Retractable coils and anchors to } \\
\text { enable optimal device positioning } \\
\text { (ii) Clinical trial data pending } \\
\text { (iii) Not in commercial use }\end{array}$ \\
\hline
\end{tabular}

C/I: contraindication and AF: atrial fibrillation.

received 4-6 weeks of Clopidogrel $75 \mathrm{mg}$ daily and subacute endocarditis prophylaxis for the initial six months due to a possible increase in infective endocarditis risk. For European patients, the choice of Clopidogrel and endocarditis prophylaxis was left at the discretion of the treating physician. Unlike subsequent trials, warfarin was not routinely prescribed as part of the trial protocol.

During the initial follow-up period of 90.7 documented implant years covering the initial postimplant period, there were 7 major adverse events in 5 patients [31]. This included 1 episode of cardiac tamponade following transseptal puncture necessitating emergent cardiovascular surgery. This patient subsequently developed a lower limb deep venous thrombosis and died secondary to cerebral haemorrhage thought secondary to anticoagulation $[31,32]$. Three other patients underwent in-hospital pericardiocentesis due to a hemopericardium [31]. Other adverse outcomes included 2 strokes occurring at 173 and 215 days postdevice implantation [31]. Their routine 1-and 6-month follow-up transesophageal echocardiograms had demonstrated stable device position with no thrombogenic layer on the device surface; colour flow doppler at six months showed "trace leak" and "absent leak." Additionally, three TIAs occurred in two patients [31]. There were six deaths in 111 patients, 
TABLE 2: Summary of antiplatelet/anticoagulation requirements and endocarditis prophylaxis for each percutaneous device.

\begin{tabular}{|c|c|c|c|c|}
\hline & Aspirin & Clopidogrel & Warfarin & Endocarditis Prophylaxis \\
\hline $\begin{array}{l}\text { AMPLATZER septal } \\
\text { occluder [28] }\end{array}$ & $\begin{array}{l}\text { Few months } \\
\text { indefinitely } \\
\text { depending on } \\
\text { treating centre }\end{array}$ & $\begin{array}{l}\text { None, few months } \\
\text { depending on treating } \\
\text { centre }\end{array}$ & $\begin{array}{l}\text { None, } 6 \text { weeks depending on } \\
\text { treating centre }\end{array}$ & Few months \\
\hline PLAATO [30] & $\begin{array}{l}300-325 \text { mg daily } \\
\text { indefinitely }\end{array}$ & $\begin{array}{l}75 \mathrm{mg} \text { for } 6 \text { months at } \\
\text { North American centres } \\
\text { and at operator's discretion } \\
\text { at European centres }\end{array}$ & Nil & $\begin{array}{l}6 \text { months at North } \\
\text { American centres and at } \\
\text { operator's discretion at } \\
\text { European centres }\end{array}$ \\
\hline WATCHMAN [33] & $\begin{array}{l}81-325 \mathrm{mg} \text { daily } \\
\text { indefinitely }\end{array}$ & $75 \mathrm{mg}$ for 6 months & $\begin{array}{l}\text { At least } 45 \text { days. Discontinued at } 45 \\
\text { days if follow up TEE shows }<5 \mathrm{~mm} \\
\text { of peridevice flow }\end{array}$ & Nil \\
\hline $\begin{array}{l}\text { AMPLATZER cardiac } \\
\text { plug [35] }\end{array}$ & Not specified & Not specified & Not specified & Not specified \\
\hline Coherex Wave Crest & $\begin{array}{l}75-325 \mathrm{mg} \text { daily } \\
\text { indefinitely }\end{array}$ & $\begin{array}{l}75 \mathrm{mg} \text { daily for } 90 \text { days if } \\
\text { not on warfarin }\end{array}$ & $\begin{array}{l}\text { If previously on warfarin with a } \\
\text { history of stroke or TIA, continue } \\
\text { warfarin until LAA closure } \\
\text { demonstrated on TEE }\end{array}$ & Nil \\
\hline LARIAT & Indefinitely & Nil & $\begin{array}{l}\text { If previous embolic events whilst on } \\
\text { OAC and no contraindication or } \\
\text { intolerance, OAC continued } \\
\text { regardless of procedural success }\end{array}$ & Nil \\
\hline
\end{tabular}

TIA: transient ischaemic attack and OAC: oral anticoagulant.

including cardiac or neurological death $(n=4)$, secondary complications after gastrointestinal bleeding $(n=1)$, and an incarcerated hernia $(n=1)$ : but none were adjudicated as related to the device or procedure [31].

At 5-year follow-up of the North American cohort of 64 patients, there were $7(11 \%)$ deaths, $5(8 \%)$ major strokes, 3 (5\%) minor strokes, 1 (2\%) cardiac tamponade requiring surgery, $1(2 \%)$, death from probable cerebral haemorrhage, and $1(2 \%)$ myocardial infarction [32]. Only 1 event (cardiac tamponade) was adjudicated as related to the implant procedure. The annualized stroke/transient ischemic attack (TIA) rate was 3.8\%: significantly less than an anticipated stroke/TIA rate of $6.6 \%$ /year as estimated by a mean CHADS2 score of 2.6 in the study population [32].

The PLAATO device has been discontinued for commercial reasons.

3.3. WATCHMAN. The WATCHMAN device (Atritech, Plymouth, MN, USA) is a percutaneous left atrial appendage closure system delivered via a transseptal approach, and implanted at or immediately distal to the ostium of the left atrial appendage. The device consists of a self-expanding nitinol frame with fixation barbs and a permeable polyester fabric which covers the atrial facing device surface. The WATHMAN device is available in 5 sizes ranging from $21 \mathrm{~mm}$ to $33 \mathrm{~mm}$ in diameter, to accommodate patient variation in left atrial appendage anatomy and size: with device sizing and placement guided by fluoroscopy and transesophageal echocardiography.

In light of the permeability of the device membrane to blood, warfarin is prescribed with a target International Normalised Ratio (INR) of 2.0 to 3.0 for a period of 45 days postdevice implantation to allow endothelialisation of the device. This is discontinued following this period, if repeat transesophageal echocardiography demonstrates either complete closure of the left atrial appendage or minimal residual peridevice flow, defined as a jet width of $<5 \mathrm{~mm}$. Following cessation of warfarin treatment, dual antiplatelet therapy with clopidogrel ( $75 \mathrm{mg}$ daily) and aspirin ( $81-325 \mathrm{mg}$ daily) was prescribed until completion of the 6-month follow-up visit, with the use of aspirin alone lifelong thereafter [33].

Evaluation of the WATCHMAN device against a conventionally treated warfarin control population was performed in the PROTECT-AF trial [33], the first trial to randomise device therapy against conventional therapy. The study randomised 707 patients, aged 18 years or older with nonvalvular atrial fibrillation and a CHADS2 risk score of $\geq 1$, in a $2: 1$ intervention to control ratio. An aggregate follow up of 1065 patient-years with mean follow up of 18 months per patient was reported. There was a good procedural success rate, with successful device implantation in 408 $(88 \%)$ of the 463 randomised to left atrial appendage closure. Following confirmation of left atrial appendage closure on transesophageal echocardiography, warfarin cessation was possible in $86 \%$. Warfarin cessation between 45 days and 6 months was attributable mainly to a reduction in peridevice leak. The WATCHMAN device was determined to be noninferior to conventional warfarin therapy when comparing the primary efficacy endpoint of strokes (ischemic and haemorrhagic), cardiovascular or unexplained death, or systemic embolism. The primary efficacy event rate was 3.0 per 100 patient-years (95\% CrI 1.9-4.5) in the intervention group compared with 4.9 per 100 patient-years (95\% CrI 2.8-7.1) in control patients receiving warfarin (Figure 2). 


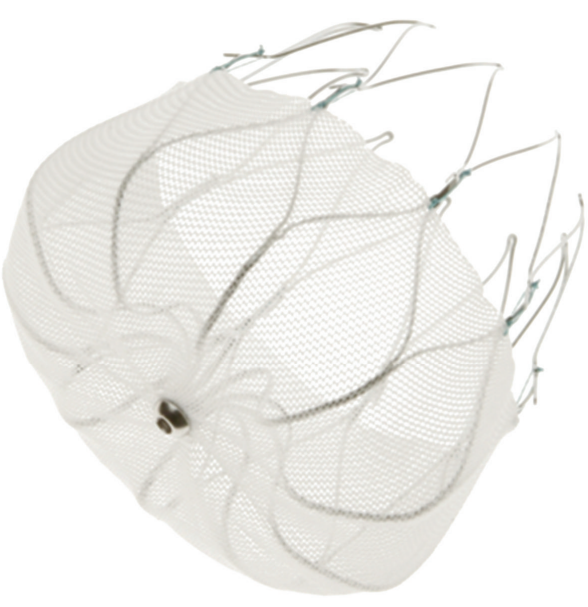

Figure 2: WATCHMAN LAA closure device. (Image courtesy of Atritech, Inc., () 2011).

However, safety concerns do exist with the placement of the WATCHMAN device: with an excess of adverse outcomes in the WATCHMAN device group compared to warfarinised controls. This is illustrated in the PROTECT-AF trail [33], where the adverse primary safety events occurred at a rate of 7.4 per 100 patient-years (95\% CrI 5.5-9.7) in the WATCHMAN group compared with 4.4 per 100 patientyears (95\% CrI 2.5-6.7). Most adverse events (55\%) were directly related to the procedure occurring on the same day as device implantation. The most frequent adverse outcome was that of a significant pericardial effusion, requiring either percutaneous or surgical drainage, carrying a $4.8 \%$ procedural risk. Other adverse procedure related outcomes included major bleeding requiring a transfusion of $\geq 2$ units of packed red cells or surgical intervention $(3.5 \%)$, procedurerelated ischemic stroke $(1.1 \%)$, device embolization $(0.6 \%)$, haemorrhagic stroke $(0.2 \%)$, oesophageal tear $(0.2 \%)$, and procedure-related arrhythmia $(0.2 \%)$. However, it should be noted that over the study duration, the incidence of major bleeding (3.5\% versus $4.1 \%)$ and haemorrhagic stroke $(0.2 \%$ versus $2.5 \%)$ was less in the intervention group compared to the control group. Further published data by Reddy et al. [33] comparing data from the first and second half of the PROTECT-AF trial with the Continued Access Protocol (CAP), suggests that device implantation is associated with a learning phase for the device implanter and that the incidence of adverse safety outcomes have declined with increasing operator experience. The data demonstrates adverse safety outcomes of $10.0 \%, 5.5 \%$, and $3.7 \%$ in the first and second halves of PROTECT AF and CAP, respectively: highlighting a decline in adverse outcome with increasing operator experience [33]. Furthermore, the FDA have mandated a subsequent follow-on randomised controlled trial (PREVAIL), aiming to enrolup to 475 patients with nonvalvular AF with a CHADS2 score of at least 2 AND be eligible for warfarin. This is a higher risk group than used in the PROTECT-AF trial. Patients will be randomised in a 2:1 fashion to receive a WATCHMAN device or warfarin only. The primary end-point is a composite of ischaemic/haemorrhagic stroke, systemic embolism and cardiovascular or unexplained death.

Early data from the ASA Plavix (ASAP) registry [34], suggest that in patients with contraindications to warfarin use, the Watchman closure device implantation is possible with the use of 6 months of dual antiplatelet therapy (aspirin and clopidogrel) followed by life-long aspirin thereafter. The registry includes 82 patients at 4 European centers in whom the device was successfully implanted with a median followup is 6 months. In this cohort with limited followup, 2 patients suffered an ischemic stroke. In both cases, no thrombus was demonstrable on the surface of the device or in the left atrium on transesophageal echocardiography. Device-related thrombus was found in 2 other patients on routine follow-up transesophageal echocardiography. Further data including longer-term followup is necessary in order to ascertain the safety and feasibility of this approach in patients with contraindications to warfarinisation.

3.4. AMPLATZER Cardiac Plug. The AMPLATZER cardiac plug (St. Jude Medical, Plymouth, MN, USA) was developed based on the AMPLATZER double-disk septal occluders (see above) designed for closure of atrial septal defects and patent foramen ovale. The AMPLATZER cardiac plug system like the other left atrial appendage occluders is designed for implantation through femoral venous access via the transseptal route.

The device consists of a lobe, designed to sit within the left atrial appendage, and an occlusive disc, which fits over the left atrial appendage orifice. The lobe and disc are connected by a central waist, with the lobe containing hooks to ensure device position.

A retrospective review of the preregistry data demonstrated good procedural success with successful device implantation achieved in 132 of the 141 patients (94\%) treated [35]. Serious adverse outcomes occurred in $10(7.0 \%)$ patients, including 3 ischemic strokes, 2 device embolization (both recaptured percutaneously), and 5 clinically significant pericardial effusions. Minor complications included 4 clinically nonsignificant pericardial effusions, 2 patients with transient myocardial ischemia, and loss of the implant in the venous system in one patient.

Interim data from the AMPLATZER Cardiac Plug's European postmarket registry reveals similar procedural success with no device embolizations during the implant procedure. Procedure related adverse events were not significantly changed when compared to the previous data, occurring in 8 out of the 145 registry patients $(5.5 \%)$ within 7 days after procedure. These consisted of 3 significant pericardial effusions, 3 device embolizations, 1 cardiac perforation, and 1 arteriovenous fistula. Three cases of thrombus on the device and one case of late device embolization were detected during the post 7-day followup (Figure 3).

The AMPLATZER cardiac plug has received European regulatory approval and is available for clinical use in Europe. Additionally, the device is currently undergoing a phase 1 randomised controlled trial compared to conventional 


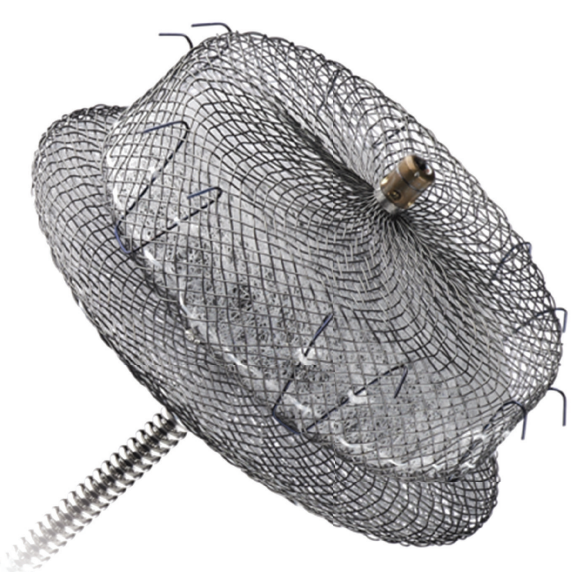

Figure 3: AMPLATZER cardiac plug. (AMPLATZER and St. Jude Medical, Inc. Reprinted with permission of St. Jude Medical, (C) 2011. All rights reserved).

warfarin therapy to obtain United States Food and Drug Administration (FDA) approval.

3.5. Coherex Wave Crest. The Coherex Wave Crest left atrial appendage occlusion system is a percutaneous transseptally delivered left atrial appendage occluder, consisting of a nitinol frame with retractable coils and anchors to enable optimal device positioning. The device consists of a multicomposite membrane including a porous expanded polytetrafluoroethylene on the left atrial side of the device, nonporous expanded polytetrafluoroethylene barrier layer, and a foam substrate on the left atrial appendage opposing surface to minimise residual leaks.

Initial pilot phase results in 9 patients demonstrated 2 embolic events, prompting device modifications prior to further trials. These modifications included provision of a bidirectional anchor, refined shape, increased radial strength, and improved occluder geometry.

The Coherex Wave Crest has thus far been implanted in 52 patients. Limited outcome data is currently available with data in a subset of 10 patients treated at a single institution revealing one embolic event with no cases of pericardial effusion or thrombosis [36]. Further clinical trial data regarding device safety and efficacy is currently pending (Figure 4).

3.6. LARIAT. The LARIAT procedure (SentreHEART Inc., Palo Alto, CA, USA) for percutaneous left atrial appendage closure requires both endocardial and epicardial access. A preoperative CT is required to exclude large bilobar appendages and other anatomic variants. A magnet-tipped guide wire system is placed at the endocardial surface of the left atrial appendage apex, via femoral venous access and a transseptal puncture. A second magnet-tipped guide wire system is percutaneously introduced into the pericardium overlying the left atrial appendage apex. This requires an anterior approach to percutaneous pericardial access using a $17 \mathrm{G}$ Tuohy needle. The magnet-tipped wires, which

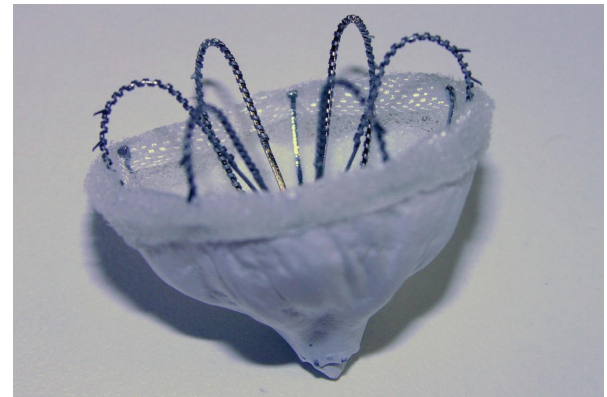

Figure 4: Coherex Wave Crest. (Image courtesy of Coherex Medi(al).

establish contact easily, align the endocardial and epicardial aspect of the left atrial appendage under fluoroscopy. The LARIAT Suture Delivery Device is guided over the left atrial appendage in an over-the-wire approach to slip a pretied suture loop over the appendage under transesophageal echocardiographic guidance to achieve appendage closure. The LARIAT delivery system can be opened and closed to allow optimal device positioning prior to device deployment [37, 38].

Due to the need for pericardial access, those patients with possible pericardial adhesions are unsuitable for the LARIAT procedure. This includes those with a prior history of cardiac surgery, pericarditis, or chest radiotherapy.

Early human experience demonstrated successful left atrial appendage ligation in 78 of 82 patients undergoing this procedure [39]. The remaining 4 patients suffered from access-related complications including 2 patients with hemopericardium, 1 patient with pericardial adhesions, and 1 patient in whom it was not possible to perform transseptal catheterization. A further 13 were excluded from undergoing this procedure, due to anatomical unsuitability and left atrial appendage thrombus on the preprocedure transesophageal echocardiogram. Of the 70 patients undergoing successful left atrial appendage ligation who had 1 month transesophageal echocardiographic followup, 96\% had complete acute closure of the left atrial appendage with the remaining $4 \%$ patients having a less than $2 \mathrm{~mm}$ jet identified by colour flow Doppler. There were no device-related complications (Figure 5).

No published postprocedural follow-up data is currently available, and further results are currently awaited.

\section{Conclusions}

Surgical methods of LAA closure have been used for more than 20 years, with varying degrees of success. Historically LAA excision has been more successful than exclusion; however, newer surgical techniques are continuously being studied. A number of percutaneous left atrial appendage closure devices are currently undergoing clinical trial. Only three of these device systems are currently available for commercial use. The LARIAT suture delivery system is the only device system with both FDA and European CE mark approval for its use. The remaining two devices 


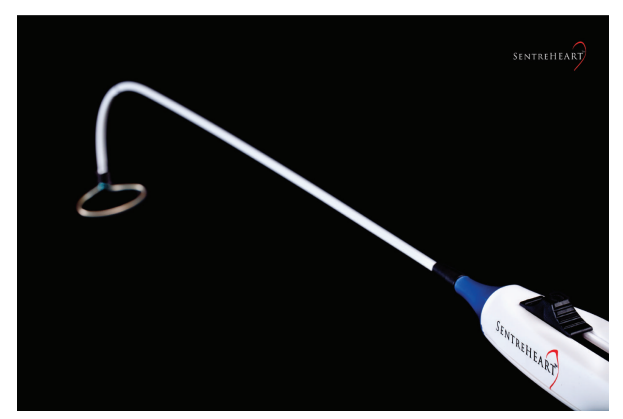

Figure 5: LARIAT (Image courtesy of SentreHEART).

(WATCHMAN and AMPLATZER cardiac plug) carry European regulatory approval for this indication. Percutaneous left atrial appendage closure devices are usually associated with high procedural success rates. However, they are also associated with a significant incidence of peri-procedural adverse events; including significant pericardial effusions, major bleeding, procedure-related ischemic stroke, device embolization, and death. Cardiac imaging plays a vital role in assessing anatomical suitability and guiding placement of these devices.

The European Society of Cardiology Guidelines for the management of Atrial Fibrillation suggests that patients with contraindications to chronic oral anticoagulation might be considered as candidates for left atrial appendage occlusion [40]. The 2011 ACCF/AHA/HRS Focused Update on the Management of Patients with Atrial Fibrillation carries no recommendations regarding percutaneous left atrial appendage closure, with the WATCHMAN device noted as currently pending FDA approval [41]. With regards to surgery, the ACC/AHA 2006 Guidelines for the Management of Patients with Valvular Heart Disease recommend patients, undergo amputation of the LAA to when a patient undergoes mitral valve surgery to reduce the incidence of postoperative thromboembolic events [42].

There is a subset of patients who are at a high risk of both cardioembolic stroke and bleeding. It is likely that these patients would be ideal candidates for LAA closure; however, its role still needs to be properly defined.

\section{Disclosure}

All authors have not received any financial support from anywhere, with regard to this paper.

\section{References}

[1] V. L. Roger, A. S. Go, D. M. Lloyd-Jones et al., "Heart disease and stroke statistics-2011 update: a report from the American Heart Association," Circulation, vol. 123, pp. e18-e209, 2011.

[2] D. M. Lloyd-Jones, T. J. Wang, E. P. Leip et al., "Lifetime risk for development of atrial fibrillation: the Framingham heart study," Circulation, vol. 110, pp. 1042-1046, 2004.

[3] C. Steger, A. Pratter, M. Martinek-Bregel et al., "Stroke patients with atrial fibrillation have a worse prognosis than patients without: data from the Austrian stroke registry," European Heart Journal, vol. 25, no. 19, pp. 1734-1740, 2004.

[4] P. A. Wolf, R. D. Abbott, and W. B. Kannel, "Atrial fibrillation as an independent risk factor for stroke: the Framingham study," Stroke, vol. 22, pp. 983-988, 1991.

[5] A. S. Go, "The epidemiology of atrial fibrillation in elderly persons: the tip of the iceberg," The American Journal of Geriatric Cardiology, vol. 14, no. 2, pp. 56-61, 2005.

[6] EAFT (European Atrial Fibrillation Trial) Study Group, "Secondary prevention in non-rheumatic atrial fibrillation after transient ischaemic attack or minor stroke," The Lancet, vol. 342, no. 8882, pp. 1255-1262, 1993.

[7] A. L. Waldo, R. C. Becker, V. F. Tapson, and K. J. Colgan, "Hospitalized patients with atrial fibrillation and a high risk of stroke are not being provided with adequate anticoagulation," Journal of the American College of Cardiology, vol. 46, no. 9, pp. 1729-1736, 2005.

[8] S. J. Connolly, J. Eikelboom, C. Joyner et al., "Apixaban in patients with atrial fibrillation," The New England Journal of Medicine, vol. 364, no. 9, pp. 806-817, 2011.

[9] S. J. Connolly, M. D. Ezekowitz, S. Yusuf et al., "Dabigatran versus warfarin in patients with atrial fibrillation," The New England Journal of Medicine, vol. 361, no. 12, pp. 1139-1151, 2009.

[10] M. T. Brown and J. K. Bussell, "Medication adherence: WHO cares?" Mayo Clinic Proceedings, vol. 86, no. 4, pp. 304-314, 2011.

[11] J. Langman, Medizinische Embryologie, Die Normale Menschliche Entwicklung und Ihre Fehlbildungen, Georg Thieme, Stuttgart, Germany, 3rd edition, 1974.

[12] J. L. Blackshear and J. A. Odell, "Appendage obliteration to reduce stroke in cardiac surgical patients with atrial fibrillation," Annals of Thoracic Surgery, vol. 61, no. 2, pp. 755-759, 1996.

[13] "Risk factors for stroke and efficacy of antithrombotic therapy in atrial fibrillation: analysis of pooled data from five randomized controlled trials," Archives of Internal Medicine, vol. 154, no. 13, pp. 1449-1457, 1994.

[14] J. L. Madden, "Resection of the left auricular appendix: a prophylaxis for recurrent arterial emboli," Journal of the American Medical Association, vol. 140, no. 9, pp. 769-772, 1949.

[15] F. C. Leonard and M. A. Cogan, "Failure of ligation of the left auricular appendage in the prevention of recurrent embolism," The New England Journal of Medicine, vol. 246, no. 19, pp. 733-735, 1952.

[16] P. M. McCarthy, A. M. Gillinov, L. Castle, M. Chung, and D. Cosgrove III, "The Cox-Maze procedure: the Cleveland Clinic experience," Seminars in Thoracic and Cardiovascular Surgery, vol. 12, no. 1, pp. 25-29, 2000.

[17] S. M. Prasad, H. S. Maniar, C. J. Camillo et al., "The CoxMaze III procedure for atrial fibrillation: long-term efficacy in patients undergoing lone versus concomitant procedures," Journal of Thoracic and Cardiovascular Surgery, vol. 126, no. 6, pp. 1822-1828, 2003.

[18] E. Raanani, A. Albage, T. E. David, T. M. Yau, and S. Armstrong, "The efficacy of the Cox/maze procedure combined with mitral valve surgery: a matched control study," European Journal of Cardiothoracic Surgery, vol. 19, no. 4, pp. 438-442, 2001.

[19] H. V. Schaff, J. A. Dearani, R. C. Daly, T. A. Orszulak, and G. K. Danielson, "Cox-Maze procedure for atrial fibrillation: Mayo Clinic experience," Seminars in Thoracic and Cardiovascular Surgery, vol. 12, no. 1, pp. 30-37, 2000. 
[20] J. L. Cox, N. Ad, T. Palazzo, and H. V. Schaff, "Impact of the maze procedure on the stroke rate in patients with atrial fibrillation," Journal of Thoracic and Cardiovascular Surgery, vol. 118, no. 5, pp. 833-840, 1999.

[21] J. S. Healey, E. Crystal, A. Lamy et al., "Left atrial appendage occlusion study (LAAOS): results of a randomized controlled pilot study of left atrial appendage occlusion during coronary bypass surgery in patients at risk for stroke," American Heart Journal, vol. 150, no. 2, pp. 288-293, 2005.

[22] A. S. Kanderian, A. M. Gillinov, G. B. Pettersson, E. Blackstone, and A. L. Klein, "Success of surgical left atrial appendage closure: assessment by transesophageal echocardiography," Journal of the American College of Cardiology, vol. 52, no. 11, pp. 924-929, 2008.

[23] E. S. Katz, T. Tsiamtsiouris, R. M. Applebaum, A. Schwartzbard, P. A. Tunick, and I. Kronzon, "Surgical left atrial appendage ligation is frequently incomplete: a transesophageal echocardiographic study," Journal of the American College of Cardiology, vol. 36, no. 2, pp. 468-471, 2000.

[24] S. P. Salzberg, A. Plass, M. Y. Emmert et al., "Left atrial appendage clip occlusion: early clinical results," Journal of Thoracic and Cardiovascular Surgery, vol. 139, no. 5, pp. 1269$1274,2010$.

[25] G. Ailawadi, M. W. Gerdisch, R. L. Harvey et al., "Exclusion of the left atrial appendage with a novel device: early results of a multicenter trial," Journal of Thoracic and Cardiovascular Surgery, vol. 142, no. 5, pp. 1002-1009, 2011.

[26] B. F. Gage, A. D. Waterman, W. Shannon, M. Boechler, M. W. Rich, and M. J. Radford, "Validation of clinical classification schemes for predicting stroke: results from the National Registry of Atrial Fibrillation," Journal of the American Medical Association, vol. 285, no. 22, pp. 2864-2870, 2001.

[27] R. Hernandez-Estefania, B. L. Praschker, G. Bastarrika, and G. Rabago, "Left atrial appendage occlusion by invagination and double suture technique," European Journal of Cardio-thoracic Surgery, vol. 41, no. 1, pp. 134-136, 2012.

[28] B. Meier, I. Palacios, S. Windecker et al., "Transcatheter left atrial appendage occlusion with AMPLATZER devices to obviate anticoagulation in patients with atrial fibrillation," Catheterization and Cardiovascular Interventions, vol. 60, no. 3, pp. 417-422, 2003.

[29] T. Nakai, M. D. Lesh, E. P. Gerstenfeld, R. Virmani, R. Jones, and R. J. Lee, "Percutaneous left atrial appendage occlusion (PLAATO) for preventing cardioembolism: first experience in canine model," Circulation, vol. 105, no. 18, pp. 2217-2222, 2002.

[30] S. H. Ostermayer, M. Reisman, P. H. Kramer et al., "Percutaneous left atrial appendage transcatheter occlusion (PLAATO system) to prevent stroke in high-risk patients with nonrheumatic atrial fibrillation: results from the international multi-center feasibility trials," Journal of the American College of Cardiology, vol. 46, no. 1, pp. 9-14, 2005.

[31] P. C. Block, S. Burstein, P. N. Casale et al., "Percutaneous left atrial appendage occlusion for patients in atrial fibrillation suboptimal for warfarin therapy: 5-year results of the PLAATO (percutaneous left atrial appendage transcatheter occlusion) study," JACC. Cardiovascular Interventions, vol. 2, no. 7, pp. 594-600, 2009.

[32] D. R. Holmes, V. Y. Reddy, Z. G. Turi et al., "Percutaneous closure of the left atrial appendage versus warfarin therapy for prevention of stroke in patients with atrial fibrillation: a randomised non-inferiority trial," The Lancet, vol. 374, no. 9689, pp. 534-542, 2009.
[33] V. Y. Reddy, D. Holmes, S. K. Doshi, P. Neuzil, and S. Kar, "Safety of percutaneous left atrial appendage closure: results from the watchman left atrial appendage system for embolic protection in patients with AF (PROTECT AF) clinical trial and the continued access registry," Circulation, vol. 123 , no. 4 , pp. 417-424, 2011.

[34] V. Y. Reddy, P. Neuzil, G. Schuler, S. Möbius-Winkler, P. Sick, and H. Sievert, "Laa closure using the watchman device in patients with contraindications to warfarin: preliminary results from the "asa plavix registry" (asap)," Journal of the American College of Cardiology, vol. 57, no. 14, p. E63, 2011.

[35] J. W. Park, A. Bethencourt, H. Sievert et al., "Left atrial appendage closure with AMPLATZER cardiac plug in atrial fibrillation: initial European experience," Catheterization and Cardiovascular Interventions, vol. 77, no. 5, pp. 700-706, 2011.

[36] D. Muller, "Coherex WaveCrest: device design and human results," in Proceedings of the Transcatheter Cardiovascular Therapeutics, 2011.

[37] R. J. Lee, K. Bartus, and S. J. Yakubov, "Catheter-based left atrial appendage (LAA) ligation for the prevention of embolic events arising from the LAA: initial experience in a canine model," Circulation: Cardiovascular Interventions, vol. 3, no. 3, pp. 224-229, 2010.

[38] L. Ganjehei, A. Massumi, M. Razavi, and A. Rasekh, "Stroke prevention in nonvalvular atrial fibrillation," Texas Heart Institute Journal, vol. 38, no. 4, pp. 350-352, 2011.

[39] R. J. Lee, K. Bartus, J. Bednarek et al., "Long-term efficacy of a percutaneous approach for LAA ligation in patients with atrial fibrillation," Heart Rhythm, vol. 8, no. 5, pp. S379-S380, 2011.

[40] J. Camm, P. Kirchhof, G.Y. Lip et al., "Guidelines for the management of atrial fibrillation: the task force for the management of atrial fibrillation of the European Society of Cardiology (ESC)," European Heart Journal, vol. 31, no. 19, pp. 2369-2429, 2010.

[41] L. S. Wann, A. B. Curtis, C. T. January et al., "2011 ACCF/ AHA/HRS focused update on the management of patients with atrial fibrillation (Updating the 2006 Guideline)," Heart Rhythm, vol. 8, no. 1, pp. 157-176, 2011.

[42] R. O. Bonow, B. A. Carabello, D. P. Faxon et al., "ACC/AHA 2006 guidelines for the management of patients with valvular heart disease: a report of the American College of Cardiology/American Heart Association Task Force on Practice Guidelines (writing committee to revise the 1998 guidelines for the management of patients with valvular heart disease) developed in collaboration with the Society of Cardiovascular Anesthesiologists endorsed by the Society for Cardiovascular Angiography and Interventions and the Society of Thoracic Surgeons," Journal of the American College of Cardiology, vol. 48, pp. e1-e148. 


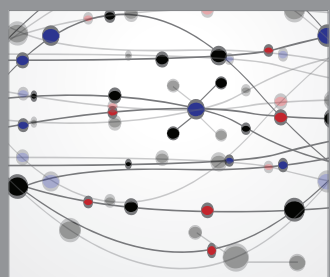

The Scientific World Journal
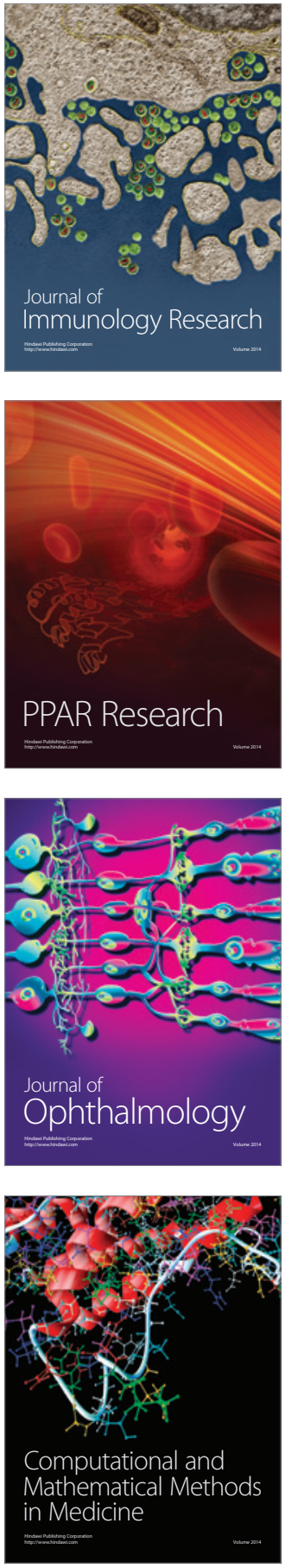

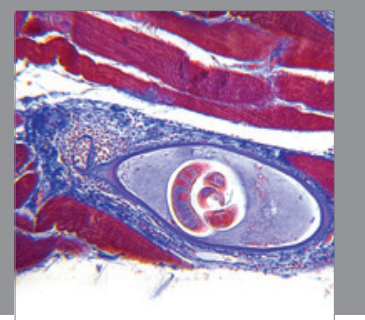

Gastroenterology

Research and Practice
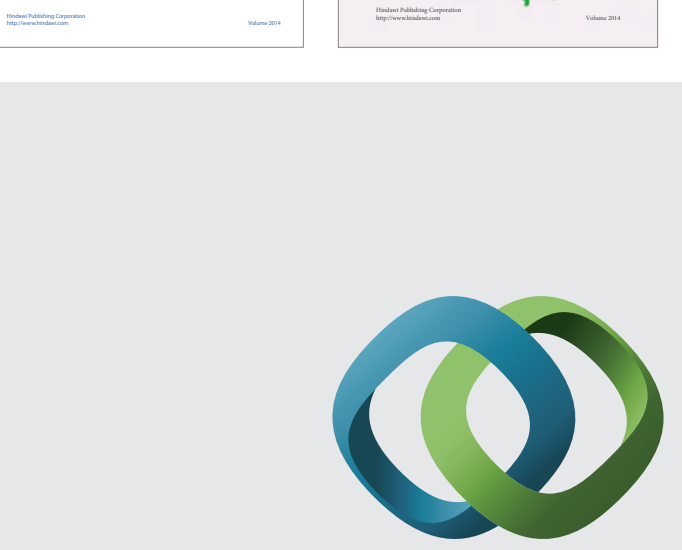

\section{Hindawi}

Submit your manuscripts at

http://www.hindawi.com
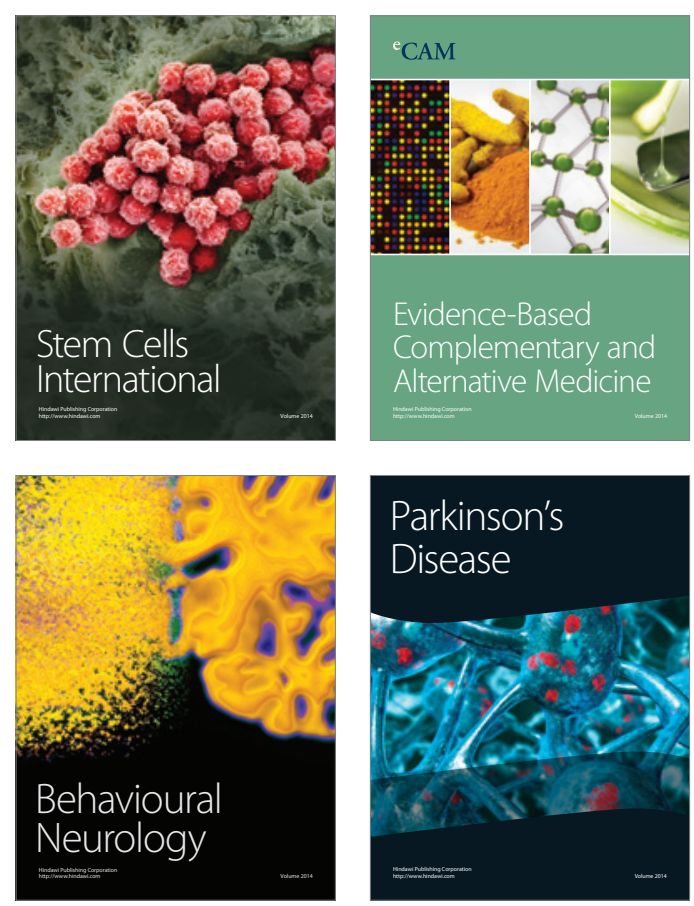

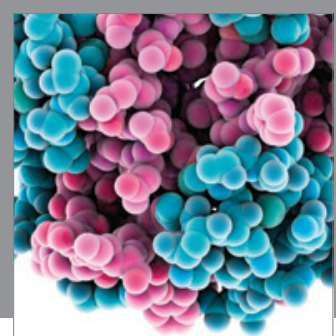

Journal of
Diabetes Research

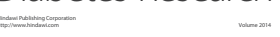

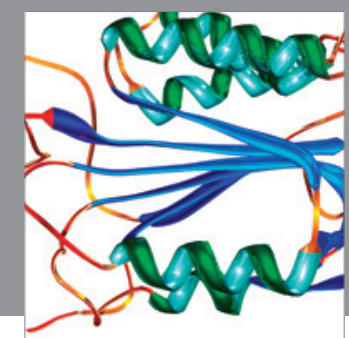

Disease Markers
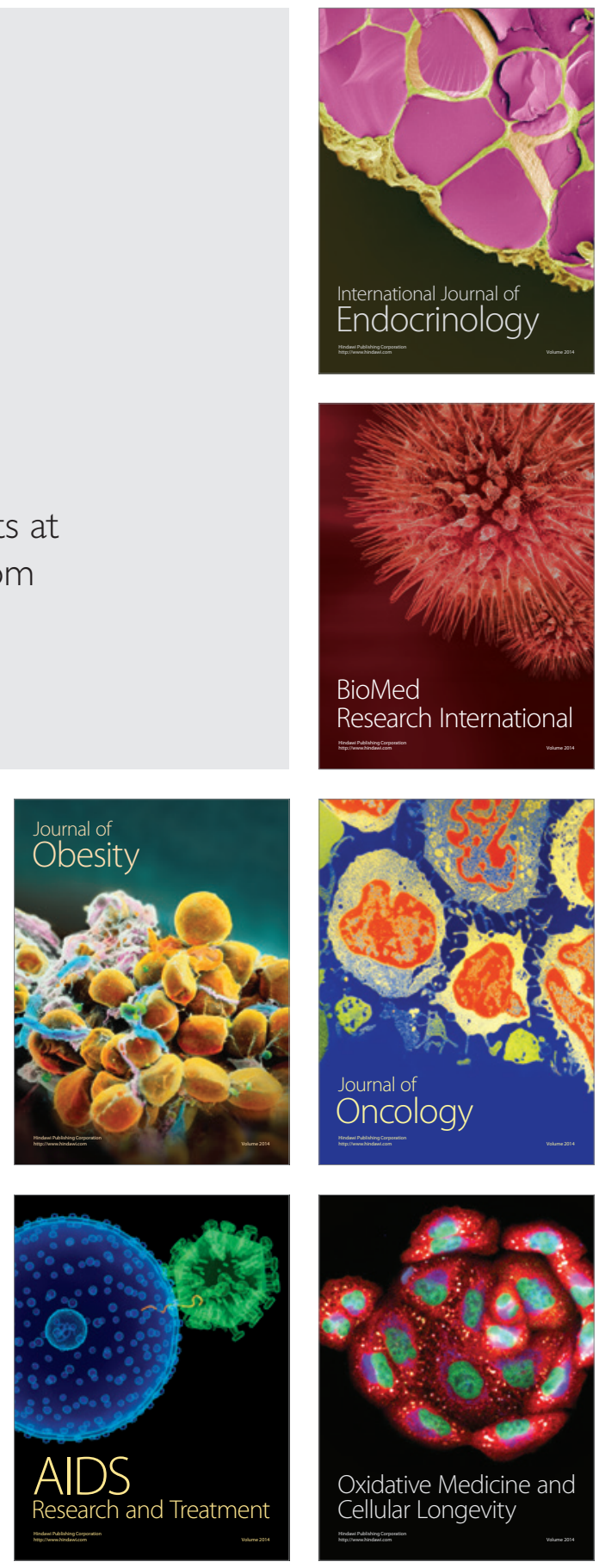